\title{
Avaliação de parâmetros comportamentais, hematológicos e sanitários na utilização de flocos de Pinus elliottii como forração de gaiolas para camundongos isogênicos
}

\author{
Danielle Cristina Gomes-Chagas, Biom., ${ }_{1}^{*}$, Juliane Pereira-Afonso, Biol., Luiz \\ Pereira da Silva, Tec. ${ }_{1}$, Anderson Domingos-Silva, Tec. ${ }_{1}$, Jonatas Pereira-Batista, \\ Tec. ${ }_{1}$, Silvia Beatriz Boscardin, $\mathrm{PhD}_{1,2}$, Cláudio Romero Farias Marinho, $\mathrm{PhD}_{1,3}$ \\ ,Biotério de Criação e Experimentação, Departamento de Parasitologia, Instituto de Ciências Biomédicas, \\ Universidade de São Paulo, São Paulo, Brasil \\ ${ }_{2}$ Laboratório de Direcionamento de Antígenos para Células Dendríticas, Departamento de Parasitologia, Instituto \\ de Ciências Biomédicas, Universidade de São Paulo, São Paulo, Brasil \\ ${ }_{3}$ Laboratório de Imunoparasitologia Experimental, Departamento de Parasitologia, Instituto de Ciências \\ Biomédicas, Universidade de São Paulo, São Paulo, Brasil.
}

Recibido: 20 de noviembre del 2015

Aprobado: 23 de febrero del 2016

*Autor de correspondência: Danielle Cristina Gomes Chagas. Universidade de São Paulo (USP), AvenIDA Professor LinEU PreStes, 1374 - CIDAdE Universitária, Butantã, São Paulo (sP), Brasil. Telefone: (+55 11) 3091-7632. Correio eletrônico: bioterioparasitologia@gmail.com

Como citar este artigo: Gomes-Chagas DC, Pereira-Afonso J, Pereira da Silva L, Domingos-Silva A, Pereira-Batista J, Boscardin SB, et al. Avaliação de parâmetros comportamentais, hematológicos e sanitários na utilização de flocos de Pinus elliottii como forração de gaiolas para camundongos isogênicos. Spei Domus. 2016;12(24). doi: http://dx.doi.org/10.16925/sp.v12i24.1889

Resumo. Introdução: a forração de gaiolas para animais de laboratório, assim como o tempo de higienização delas, é um dos fatores mais importantes para seu microambiente. Este trabalho teve como objetivo avaliar dois tipos de forração de gaiolas, com tempo de higienização quinzenal. Metodologia: avaliamos dois tipos de forração de gaiolas, provenientes da madeira com gramaturas diferenciadas, maravalha e flocos de Pinus elliottii. Os animais foram pesados e medidas das patas traseiras foram aferidas semanalmente. Dados de comportamento, como movimentação nas gaiolas, nidificação, mortalidade, fertilidade, entre outros, também foram realizados durante todo o estudo por meio de gravações noturnas e diurnas, assim como amostras de sangue foram coletadas para análise hematológica. Resultados: a forração de gaiolas com flocos de Pinus foi considerada uma eficaz substituição à de maravalha na higienização quinzenal; na avaliação fisiológica, não houve diferença significativa entre as duas forrações quanto a peso, temperatura e medida das patas traseiras; já na análise hematológica entre os grupos, os animais mantidos em gaiolas com forração de maravalha com higienização quinzenal apresentaram um aumento nos valores de hematócrito. Esses resultados foram corroborados pelo exame histopatológico dos pulmões de animais Balb/c, que revelaram congestão pulmonar, edema peribronquiolar e peripleural sugerindo síndrome respiratória. Conclusões: o flocos de Pinus foi considerado uma boa opção como forração de gaiolas, visto que o material foi considerado eficaz por não trazer danos respiratórios aos animais mantidos em confinamento pelo período de duas semanas sem higienização e por manter o mesmo perfil de comportamento que a maravalha de Pinus.

Palavras-chave: Balb/c, bem-estar, estresse, forração de gaiolas, sistema de alojamento. 


\title{
Evaluation of behavioral, hematological and sanitary parameters in the use of Pinus elliottii flakes as cage lining for isogenic mice
}

\begin{abstract}
Introduction: The cage lining for laboratory animals, as well as their cleaning frequency, is one of the most important factors for their micro-environment. The purpose of the work was to evaluate two types of cage lining, with a biweekly cleaning frequency. Method: Two types of cage lining, made of wood with different weights, sawdust and flakes of Pinus elliottii, were evaluated. Animals were weighed and their hind legs measured weekly. Data on behavior such as movement in the cages, nesting, mortality, fertility, among others, were also gathered throughout the study by means of day and night recordings, as well as blood samples for hematological analysis. Results: Cage lining with Pinus elliottii flakes was considered an effective replacement for sawdust in biweekly cleaning; in the physiological evaluation, there was no significant difference between the two linings in terms of weight, temperature and measurement of the hind legs; in the hematological analysis between groups, the animals kept in cages with sawdust lining and biweekly cleaning already showed an increase in hematocrit values. These results were corroborated by histopathological examination of the lungs of $\mathrm{Balb} / \mathrm{c}$ animals that revealed pulmonary congestion, peribronchiolar and peripleural edema suggesting respiratory syndrome. Conclusions: The Pinus flake was considered a good choice for cage lining once the material was effective because it did not cause respiratory damage to animals kept in confinement for a period of two weeks without cleaning and because it maintained the same behavior profile than Pinus sawdust.
\end{abstract}

Keywords: Balb/c, welfare and stress, cage lining, accommodation system.

\section{Evaluación de los parámetros conductuales, hematológicos y sanitarios en la utilización de copos Pinus elliottii como forrado de jaulas para ratones isogénicos}

Resumen. Introducción: el forrado de jaulas para animales de laboratorio, así como el tiempo de higienización de estas, es uno de los factores más importantes para su micro-ambiente. El trabajo tuvo como finalidad evaluar dos tipos de forrado de jaulas, con tiempo de higienización quincenal. Metodología: se evaluaron dos tipos de forrado de jaulas, provenientes de la madera con gramajes diferenciados, aserrín y copos de Pinus elliottii. Se pesaron los animales y se midieron sus patas traseras semanalmente. Datos de la conducta como circulación en las jaulas, nidificación, mortalidad, fertilidad, entre otros, también se realizaron durante todo el estudio por medio de grabaciones nocturnas y diurnas, así como se tomaron muestras de sangre para análisis hematológico. Resultados: el forrado de jaulas con copos de Pinus elliottii se consideró un eficaz reemplazo al de aserrín en la higienización quincenal; en la evaluación fisiológica, no hubo diferencia significativa entre los dos forrados en cuanto a peso, temperatura y medida de las patas traseras; ya en el análisis hematológico entre los grupos, los animales mantenidos en jaulas con forrado de aserrín con higienización quincenal presentaron un incremento en los valores de hematocrito. Estos resultados fueron corroborados por el examen histopatológico de los pulmones de animales Balb/c que revelaron congestión pulmonar, edema peribronquiolar y peripleural que sugiere síndrome respiratorio. Conclusiones: el copo de Pinus se consideró una buena opción para el forrado de jaulas una vez que el material resultó eficaz por no traer daños respiratorios a los animales mantenidos en confinamiento por el periodo de dos semanas sin higienización y por mantener el mismo perfil de conducta que el aserrín de Pinus.

Palabras clave: Balb/c, bienestar y estrés, forrado de jaulas, sistema de alojamiento. 


\section{Introdução}

Pouco se sabe sobre quais características podem contribuir especificamente para uma possível mudança fenotípica nos animais de laboratório. No entanto, a forração de gaiolas animal é um dos fatores mais importantes do ponto de vista do microambiente e pode ter influência direta no bem-estar animal e, consequentemente, nos dados experimentais obtidos com eles [1-5]. Materiais para forração de gaiolas vêm demostrando ter um valor peculiar nas alterações comportamentais dos animais de laboratório, inclusive influenciando no estresse, no perfil imunológico, na termorregulação, na massa corporal e nos níveis de enzimas hepáticas [5]. A forração de gaiolas para animais de laboratório pode gerar poluentes ambientais tais como pó e, quando na presença dos excrementos animais, gerar amônia ( $\left.\mathrm{NH}_{3}\right)$, considerados grandes vilões tanto para o animal quanto para seu tratador. A amônia é produzida pela degradação da ureia eliminada na urina dos animais. A gaiola é considerada um ambiente favorável à proliferação de bactérias devido à sua umidade; isso impede que os excrementos ressequem, tornando-se um ambiente favorável para o crescimento de bactérias uréase-positivas, como é o caso Klebsiella pneumoniae, altamente patogênica para colônia de camundongos. Animais expostos a altas concentrações de amônia podem desenvolver severas irritações na mucosa dos olhos e trato respiratório, incluindo inflamação das vias nasais, rinite e necrose do epitélio olfativo $[6,7]$. A forração de gaiolas animal possui várias funções, entre elas: absorver a urina dos animais, aquecê-los e controlar ou mesmo reduzir a umidade $[8,9]$. Por esse motivo, o material escolhido para forração de gaiolas deve ter alta capacidade de absorção da umidade, mas que não desidrate ou machuque os animais e principalmente os neonatos. Além disso, não deve conter poeira nem ser abrasivo e, principalmente, deve estar livre de agentes químicos ou patogênicos [3-10]. Atualmente, o material mais utilizado para esse fim é a raspa de madeira, comumente conhecida como maravalha, que advém de inúmeros tipos de madeira, como a Aspen e a Pinus. Outros tipos de materiais ainda são muito estudados como a palha e o sabugo de milho $[3,7,11]$. Estes dois últimos estão sendo utilizados com mais frequência como alternativa na diminuição da amônia nas gaiolas de animais de laboratório.
Em 2003, Domer et al. [12] realizaram um estudo com diversos materiais a fim de identificar a carga microbiana, a quantidade de pó e os tipos de sujidades encontrados nos materiais mais utilizados em biotérios europeus. Sua preocupação estava na qualidade sanitária, pois a saúde dos animais poderia ser comprometida, caso o material estivesse contaminado [12]. A qualidade do produto deve garantir que este não tenha entrado em contato com roedores silvestres e/ou pássaros, considerados principais vetores de doenças que acometem os animais de laboratório. Ainda sobre alguns tipos de forração de gaiolas, recentemente Ambery 2014 [13] realizou um estudo comparativo no qual ele observou que existe uma diferença significativa da microbiota, quando há mudança do material utilizado na formação da forração de gaiolas. O estudo comparou forração de gaiolas formadas por papel reciclado e sabugo de milho, em ensaio que utilizou camundongos c57BL/6 com dieta hipercalórica para animais pré-diabéticos. Os animais mantidos na forração de gaiolas de sabugo de milho, e com dieta hipercalórica, tiveram redução de peso, enquanto, na dieta hipocalórica, tiveram maior ganho de massa corporal, correlacionando com estudos anteriores que indicam que a mudança de forração de gaiolas pode modular a microbiota do animal, o que traz ou não benefícios ao protocolo de experimentação e criação $[10,13,14]$.

Apesar de o sabugo de milho ser uma nova escolha no ambiente de animais de laboratório, não podemos negligenciar fatores relacionados ao bem-estar desses roedores. Leys, McGaraughty e Radek [15] realizaram um trabalho com ratos Wistar no qual observaram que animais mantidos nesse tipo de forração de gaiolas dormiam menos quando comparados a animais mantidos na maravalha de Aspen. Durante o estudo comportamental, realizado por cinco semanas, os animais afastavam o sabugo de milho e dormiam na superfície limpa da gaiola. Esse fato é considerado relevante para animais de laboratório, já que o sono adequado é essencial para o funcionamento fisiológico saudável. Dessa forma, quando há alterações ou distúrbios, existe a possibilidade de haver alterações neurocomportamentais, fisiológicas e até mesmo imunológicas no indivíduo $[15,16]$.

Do ponto de vista da absorção, a maravalha feita com a madeira de Aspen apresenta-se menos eficiente em relação ao sabugo de milho, que possui maior capacidade de absorção e diminuída 
quantidade de pó quando comparada a outros materiais como as tiras de papel; estas, por sua vez, apresentam menor toxicidade para os animais do que o sabugo de milho, devido à diminuída concentração de endotoxinas [10, 17].

Outro fator importante, e ainda pouco discutido na comunidade científica de ciência de animais de laboratório, é a frequência da higienização das gaiolas dos roedores. É sabido que a "cama" é o ambiente mais próximo do animal e que deve representar o ambiente mais semelhante possível ao da natureza; no caso dos camundongos, não só as condições para nidificação e absorção são importantes, o odor também é, uma vez que a identificação e o reconhecimento dos indivíduos se fazem pelo cheiro. É por meio dos feromônios que machos e fêmeas se acasalam e determinam território; assim, a cada mudança ou higienização das gaiolas, existe uma desestruturação do microambiente. Dessa forma, um animal em situação de confinamento que enfrenta semanalmente essa situação de higienização pode passar pelo estresse e trazer mal-estar e perfis agressivos como canibalismo [18-20]. O sistema fechado ventilado (Individually Ventilated Cages - IVC) tem sido adotado em diversos biotérios de criação e experimentação, por isso ainda existem poucos trabalhos que relatem o tempo necessário para higienização das gaiolas de acordo com o material, uma vez que para sistema aberto já há preconizações em guias nacionais e estrangeiros. Embora a higienização seja essencial para o microambiente e assegure a integridade sanitária do animal e de seu tratador, pois o acúmulo de dejetos e umidade pode aumentar a proliferação de bactérias e maior acúmulo de NH3, essa conduta pode trazer prejuízos aos animais em confinamento, principalmente devido aos feromônios. Em 2014, um grupo da Califórnia [6] estudou quatro tipos de forração de gaiolas: a maravalha de Aspen nova e reciclada, tiras de papel e sabugo de milho, com intuito de avaliar qual o melhor tempo de higienização para cada material, levando em consideração a capacidade de absorção da amônia e alterações histopatológicas. Os resultados da medida de amônio mostraram, juntamente com os achados histopatológicos, que evidenciaram edema e congestão nasal, que a maravalha reciclada deveria ser higienizada aproximadamente a cada três dias de acordo com a dosagem de amônia, que nesse momento já era superior a $150 \mathrm{ppm}$. Já nos outros materiais, sabugo de milho, maravalha nova e tiras de papel, a higienização foi indicada a partir do sétimo dia, quando os níveis de amônia já estavam mais elevados. Esse trabalho corrobora os dados apresentados por Rosenbaum [21], que realizou um estudo com 20 tipos de forração de gaiolas formadas por esses quatro materiais. Os dados que verificaram a eficiência dos diferentes materiais mostraram que, em termos de maior absorção e utilização de menor volume de material para forração de gaiolas, o sabugo de milho foi melhor em comparação com as tiras de papel, as quais, por sua vez, foram melhores que a maravalha [21].

Além disso, o tempo de higienização e o manejo de animais interrompem o comportamento natural, visto que o ninho ou o processo de nidificação é desfeito assim como a demarcação de território, que é normalmente feita pelos machos, se perde, o que pode levar a um comportamento agressivo e aumentar as taxas de infanticídio, mortalidade e diminuição na reprodução. Podemos ainda contar com dados robustos que indicam que o manejo em períodos mais curtos aumenta taxas de corticosteroides no sangue [21].

De um modo sucinto, as instituições e os guias práticos de cuidados de animais de laboratório sugerem um período de higienização de três a sete dias, dependendo do material, da gestão do biotério e, principalmente, da relação custo-benefício $[6,10,21,22]$.

Assim, o objetivo deste trabalho foi avaliar dois tipos de forração de gaiolas provenientes da madeira, mas com gramaturas diferenciadas. A escolha do produto teve por base o menor custo e a maior frequência de utilização dentro das instituições brasileiras, pois o flocos de Pinus é uma alternativa na busca de forração de gaiolas com qualidade sanitária, que atendam às necessidades fisiológicas e comportamentais dos animais de laboratório, além de trazer novas alternativas na gestão de biotérios.

\section{Materiais e Métodos}

\section{Animais}

Foram utilizados 40 fêmeas e 40 machos de camundongos da linhagem isogênica Balb/c, mantidos no Biotério do Departamento de Parasitologia da Universidade de São Paulo (ICB-USP) pelo período 
de dez semanas, sob condições convencionais com barreiras sanitárias. Os animais foram mantidos em estantes ventiladas (Alesco al 26), com ciclos de fotoperíodo claro e escuro de 12 horas, umidade relativa fixada na faixa de 45 a $55 \%$, temperatura controlada de $22+/-2{ }^{\circ} \mathrm{C}$ e higienização de ar de 35 higienizações/hora. A água, tratada em autoclave (a $121^{\circ} \mathrm{C}$ por $20 \mathrm{~min}$ ), e a ração (Quimtia ae 7), autoclavada a $121^{\circ} \mathrm{C}$ por 20 minutos, foram fornecidas ad libitum. A higienização das gaiolas foi realizada conforme cada protocolo de experimentação. Todos os procedimentos foram realizados de acordo com os princípios internacionais de bem-estar animal, e o projeto foi aprovado pela Comissão de Ética no Uso de Animais (Ceua 19/2013) do Instituto de Ciências Biomédicas da Universidade de São Paulo.

\section{Protocolo experimental}

Os animais foram desmamados aos 21 dias e alojados em microisoladores da marca Alesco, confeccionados em polissulfona, nas medidas $32 \mathrm{~cm}$ comprimento $\times 20 \mathrm{~cm}$ de largura $\times 21 \mathrm{~cm}$ de altura. Com tampa de encaixe e elemento filtrante descartável, higienização a cada 15 dias para verificação de acúmulo de pó. Os animais foram separados em grupos de cinco animais por gaiola e foram distribuídos em dois grupos de quatro gaiolas cada um.

Grupo 1 - Forração de gaiolas de maravalha de Pinus elliottii com 90 gramas do material.

Grupo 2 - Forração de gaiolas de flocos de Pinus elliotii com 90 gramas do material.

Inicialmente, todas as gaiolas foram higienizadas semanalmente, no mesmo dia e horário e com o mesmo tratador. Após três semanas, a higienização foi realizada a cada 15 dias para ambos os grupos. Os animais foram pesados semanalmente, e a medida das patas traseiras foi realizada com auxílio de um paquímetro, a fim de identificar se o material utilizado seria capaz de causar inchaço. A temperatura das gaiolas também foi aferida semanalmente com auxílio de um termômetro digital.

\section{Padrão de comportamento}

Os animais foram filmados utilizando uma câmera Sony (Cyber-Shot dsc-h50) nos dias 1, 5 e 15 por um período de 10 minutos, sendo que o dia 1 foi o início do contato dos animais com o flocos de Pinus elliotii, pois a criação era realizada em maravalha. O comportamento dos animais foi observado durante todo o período de alojamento nos distintos materiais, diariamente por meio de anotações. Isso incluiu sinais de briga, feridas, vocalização, disposição espacial, odor e sujidade. Esta última foi anotada com cruzes de acordo com odor e sujidade, sendo que + era pouco ou quase não detectável, ++ suportável e +++ insuportável.

\section{Hematológico}

Ao final das dez semanas alojados em forração de gaiolas diferentes, cinco animais de cada grupo foram selecionados randomicamente e, sem prévio jejum, foram coletadas amostras de sangue total em tubos heparinizados através de punção da veia submandibular. As amostras foram analisadas na mesma data da coleta em equipamento automatizado bc-28000vet (Mindray). Os parâmetros hematológicos do eritrograma e leucograma de cada animal macho e fêmea foram analisados estatisticamente no programa GraphPad Prism 5.0 (Two-Way-anova pós-teste Bonferroni).

\section{Análise microbiológica}

No recebimento do material não estéril, foram retiradas 25 gramas de amostra de cada saco de maravalha e flocos, acondicionadas em frascos de 500 $\mathrm{mL}$, que continham $225 \mathrm{~mL}$ de água peptonada 0,1 $\%$ ou meio líquido enriquecido BHI (brain heart infusion). Em seguida, as amostras foram homogeneizadas em vortex e colocadas em repouso pelo período de 60 minutos. Após esse procedimento, realizou-se uma diluição de 1:100.000, e $100 \mu \mathrm{l}$ desse material foram semeados em placas de ágar Müeller-Hinton (meio não seletivo), ágar MacConkey (seletivo e diferencial para gram-negativos e enterobactérias) e meio ágar sangue (meio enriquecido e diferencial para bactérias exigentes), com auxílio da alça de drigalski descartável estéril. O plaqueamento foi realizado pelo método "spread plate", e as placas foram incubadas por 24 horas em estufa bacteriológica $36,5 \pm 2^{\circ} \mathrm{C}$ [23]. Após esse período, realizou-se a contagem manual de unidades formadoras de colônias por placa (ufc/placa) avaliando-se o crescimento em meio seletivo para enterobactérias, que foram em seguida identificadas bioquimicamente por meio de kit comercial de 
identificação Bactray 1, 2 e 3, no intuito de quantificar e avaliar a qualidade sanitária dos materiais recebidos. Não foram realizados antibiogramas ou testes adicionais que não fossem pertinentes à identificação fenotípica das bactérias isoladas.

\section{Histopatologia}

Foram selecionados aleatoriamente dois animais de cada grupo para análise histopatológica, após o período de experimentação. Depois da eutanásia, foi realizada uma laparotomia e foram retirados os seguintes órgãos: coração, baço, fígado e pulmão. Todos os órgãos foram imersos em formaldeído tamponado a $15 \%$. No laboratório de Patologia/Histologia, as peças foram preparadas a partir dos seguintes passos: desidratação em álcool; diafanização em Xilol; inclusão em parafina; cortes de $4 \mu \mathrm{m}$ usando um micrótomo; banho-maria e captura da seção de tecido; secagem em estufa; desparafinação com Xilol; banhos de álcool; coloração com Hematoxilina e, posteriormente, Eosina. Por fim, aplicação do Bálsamo do Canadá e colocação da lamínula a fim de proteger o corte. Com as lâminas prontas, foi possível analisá-las à microscópica óptica. 6

\section{Resultados}

Para a utilização dos materiais na formação da forração de gaiolas, fizemos uma análise microbiológica das amostras antes do processo de esterilização. A tabela 1 mostra um crescimento bacteriano significativo na maravalha de Pinus elliotii, incluindo o isolamento de colônias de enterobactérias e bactérias gram-negativas não fermentadoras (Pseudomonas aeruginosa). Após o processo de autoclavação do material, não houve crescimento bacteriano considerável.

Tabela 1. Análise microbiológica

\begin{tabular}{|c|c|c|c|}
\hline Contagem & Identificação & Contagem & Identificação \\
\hline \multirow[t]{2}{*}{$>10^{5} \mathrm{UFC} / \mathrm{g}$} & Fungos filamentosos & $90 \mathrm{UFC} / \mathrm{g}$ & Fungos filamentosos \\
\hline & Sthapylococus & & Staphlococcus capitis \\
\hline \multirow[t]{3}{*}{$>10^{8} \mathrm{UFC} / \mathrm{g}$} & Enterobactérias & $>10^{8} \mathrm{UFC} / \mathrm{g}$ & Enterococcus sp \\
\hline & Pseudomonos sp & & Basillus sp \\
\hline & Bocillus sp & & \\
\hline \multicolumn{4}{|c|}{ ESTERILIZAÇÃO AUTOCLAVE - 20 MIN } \\
\hline Contagem & Identificação & Contagem & Identificação \\
\hline $5 \mathrm{UFC} / \mathrm{g}$ & Fungos filamentosos & $2 \mathrm{uFC} / \mathrm{g}$ & Fungos filamentosos \\
\hline $10 \mathrm{UFC} / \mathrm{g}$ & Bacillus sp & $2 \mathrm{UFC} / \mathrm{g}$ & Bacillus sp \\
\hline
\end{tabular}

Fonte: os autores

No estudo relacionado ao comportamento dos animais ante as duas forrações de gaiolas, podemos observar que, no primeiro contato com a forração de gaiolas de flocos de Pinus elliotii (gravação de $30 \mathrm{~min}$ ), os animais fizeram o reconhecimento do microambiente por meio da escavação, comportamento considerado natural da espécie, assim como a demarcação de território. Passando-se as três semanas com higienização a cada sete dias, sem nenhuma observação digna de nota, do ponto de vista de estresse e agressividade, notamos que os grupos mantidos em maravalha higienizados a cada 15 dias começaram a desenvolver sinais de distúrbio de comportamento, como apatia, agressividade e mutilação de outros animais, somente nas gaiolas de machos (dados não mostrados), enquanto nos animais mantidos em forração de flocos, não apresentaram tais condutas. 
No quesito sujidade (figura 1), podemos observar que no Grupo i (forração de gaiolas de maravalha), gaiolas com cinco animais, apresentavam-se mais sujas com 7 e 15 dias quando comparadas ao Grupo II (forração de gaiolas de flocos). Esse parâmetro foi considerado importante, pois pode desencadear um microambiente não adequado aos animais, com uma maior concentração de $\mathrm{nh}_{3}$ nas gaiolas, o que remete ao aumento de umidade e da possibilidade de proliferação de bactérias uréases-positivas.

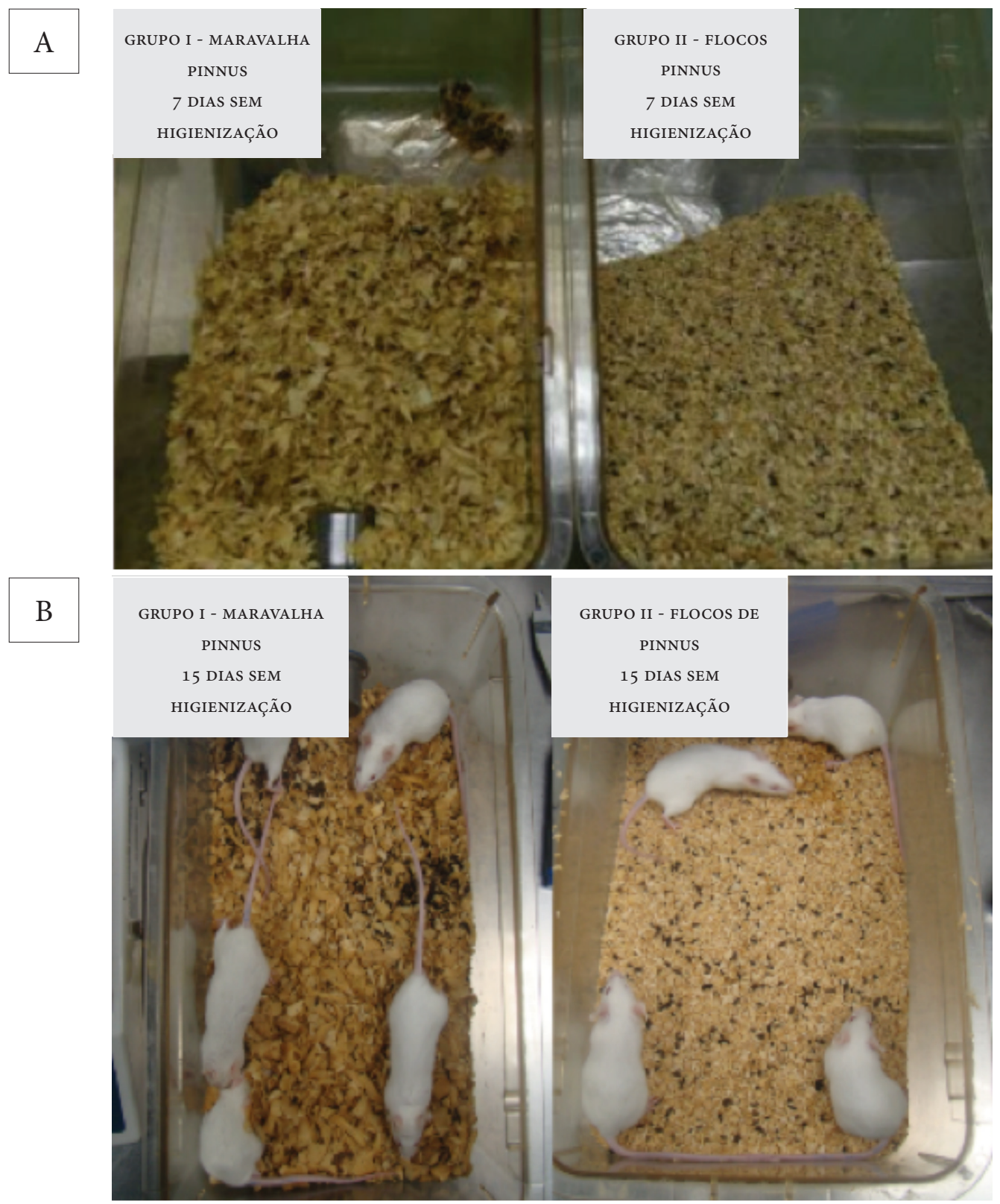

Figura 1. Comparação Sujidade

Compara os grupos I e II (maravalha e flocos), respectivamente, em dias diferenciados de higienização. A: após 7 dias e B: após 15 dias.

Fonte: os autores. 
Com relação ao ganho de peso, não houve diferença significativa entre os grupos, nem entre os sexos (figura 2).

A)

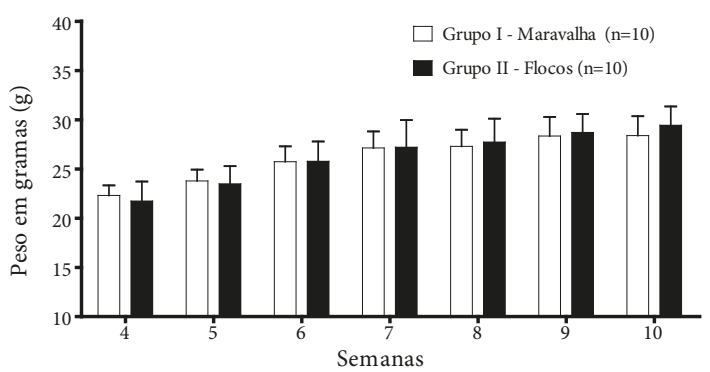

B)

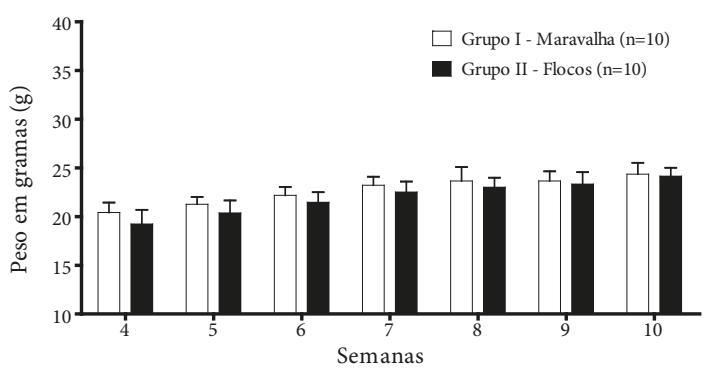

Figura 2. Ganho de Peso. Análise da média de peso semanal

A: animais machos e B: animais fêmeas nos dois tipos de forração de gaiolas.

Fonte: os autores.

Quanto às patas traseiras (Figura 3), não observamos nenhum tipo de ferida, inchaço ou escoriações que modificassem sua medida $(\mathrm{mm})$ em nenhum animal. Essa avaliação é considerada de grande importância, pois abrange a possibilidade de avaliarmos possíveis causas na diminuição da mobilidade do animal nas gaiolas.

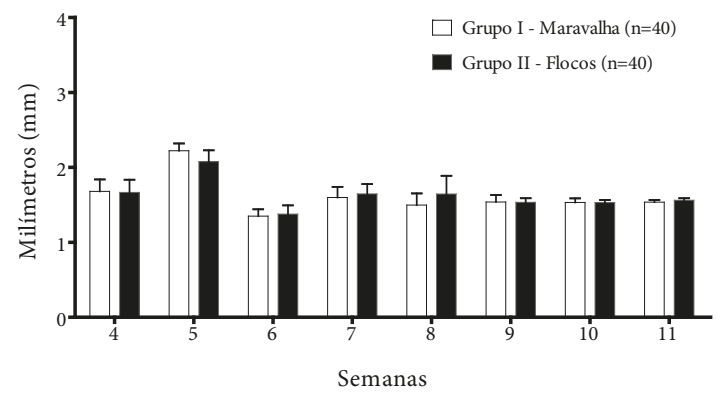

Figura 3. Avaliação da medida das patas traseiras O gráfico avalia a média das patas traseiras nos dois grupos de forração de gaiolas e em ambos os sexos.
Fonte: os autores

A aferição da temperatura das gaiolas foi realizada quinzenalmente, e a média nas duas forrações de gaiolas foi de $27 \pm 2^{\circ} \mathrm{C}$, além de não ter sido observado vazamento de água em nenhuma gaiola (figura 4).

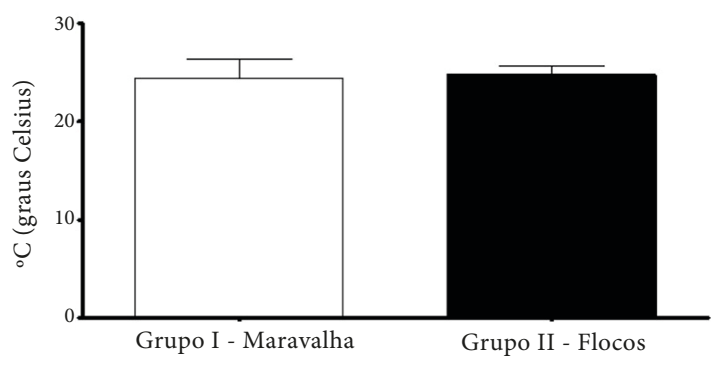

Figura 4. Média de temperatura

Avaliação representada em média \pm desvio padrão da temperatura das gaiolas em forração de gaiolas diferentes.

Fonte: os autores.

Ao final do experimento, foram selecionados randomicamente cinco machos e cinco fêmeas de cada grupo para análise hematológica (figura 5). Observamos que houve um aumento significativo nos machos do Grupo I (maravalha, $\mathrm{p}<0,001$ ) nos parâmetros relacionados à contagem percentual de hematócrito. A elevação desse parâmetro pode estar relacionada a desidratação, diminuição de oxigênio e distúrbios cardiopulmonares. Na contagem total de hemácias e hemoglobina, não houve diferenças entre os grupos e os sexos. A contagem diferencial de linfócitos e neutrófilos pelo leucograma (figura 6) não mostrou diferença entre os grupos e os sexos.

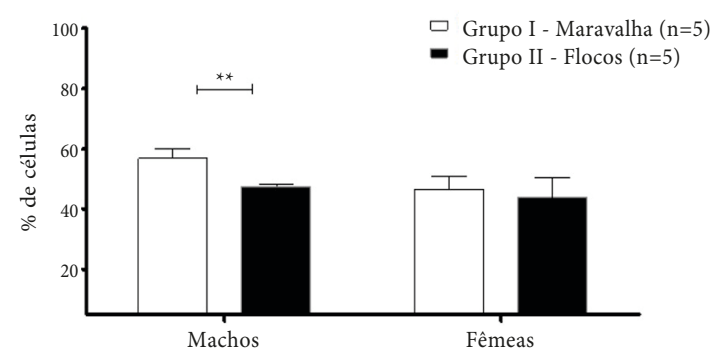

Figura 5. Eritrograma

Percentagem de HCT (Hematócrito) em ambos os sexos e entre os grupos I (maravalha) e II (flocos). Análise estatística Two Way ANOVA pós-teste Bonferroni (*** $\mathrm{p}<0,01)$.

Fonte: os autores. 

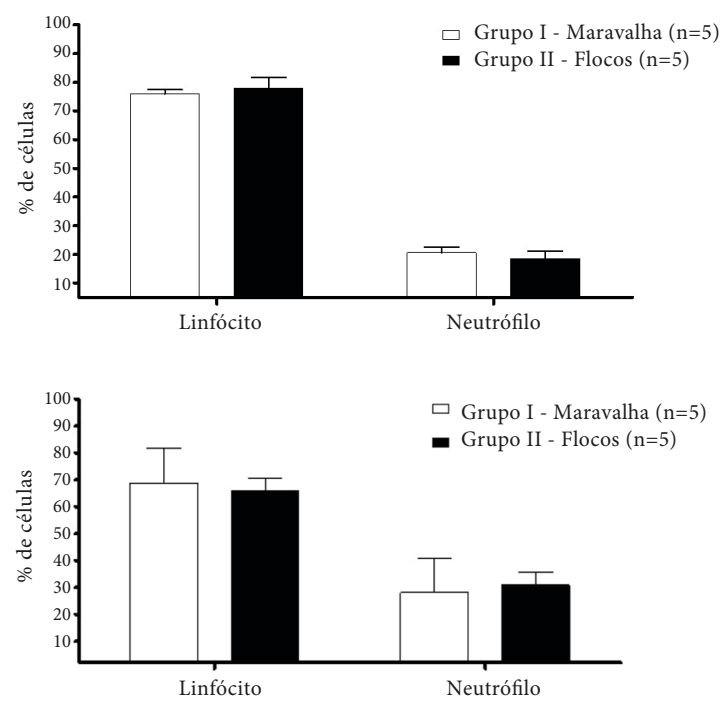

Figura 6. Leucograma

A: animais machos e B: animais fêmeas. Percentagem de linfócitos e neutrófilos em ambos os sexos e entre os grupos I (maravalha) e II (flocos).

Fonte: os autores.
Realizamos análises histopatológicas em dois animais de cada grupo e não observamos alterações micro e macroscópicas nos rins, intestinos, baço, coração e pâncreas entre os tipos de forração de gaiolas (dados não mostrados). No entanto, a análise macroscópica dos pulmões dos animais do Grupo I (maravalha) mostrou congestão cranial, enfisema e moderada inflamação, o que corrobora com a análise microscópica (figura 7) que revelou intensa congestão, seguida de edema peribronquiolar e peripleural $(n=4)$. Consideramos animais da mesma linhagem e higienização das gaiolas semanalmente como controle para este experimento. 


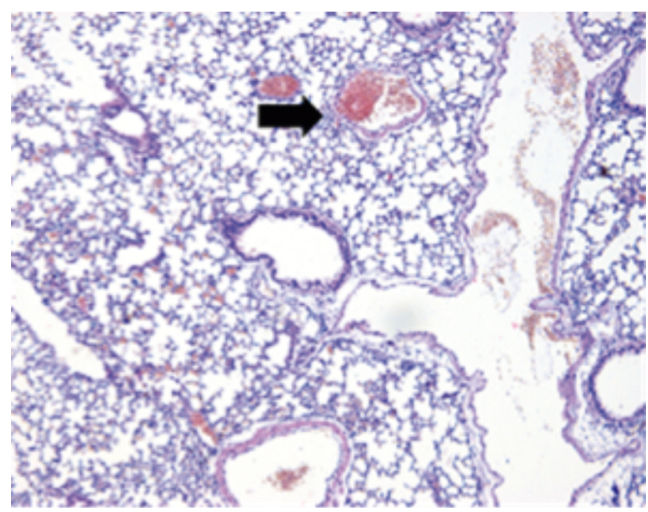

A - Controle biopsia pulmão - IVC Maravalha com troca semanal.

Aumento 200X

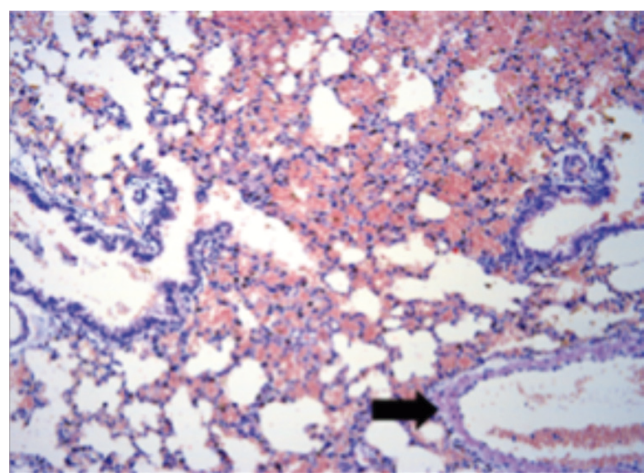

C—Grupo I biopsia pulmão - IVc Maravalha Higienização quinzenal.

Aumento 200X

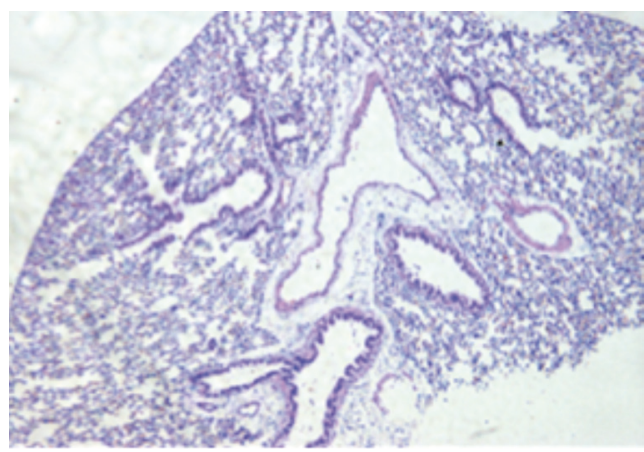

E- Grupo I biopsia pulmão - IVC Flocos Higienização quinzenal.

Aumento 200X

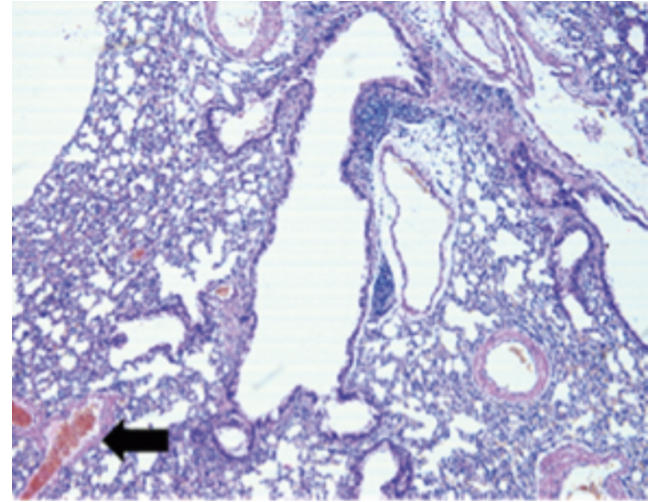

B - Controle biopsia pulmão - IVC Maravalha com troca semanal.

Aumento 100X

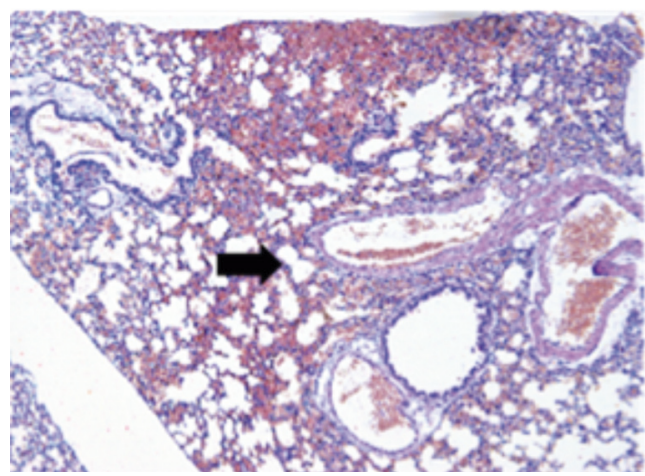

D—Grupo I biopsia pulmão - IVc Maravalha Higienização quinzenal.

Aumento 100X

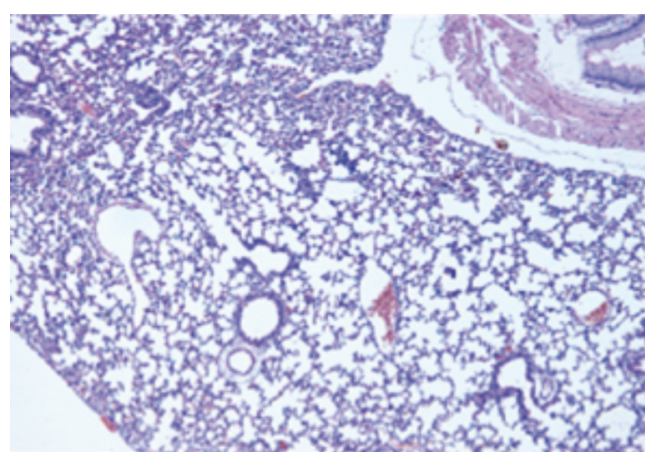

F- Grupo I biopsia pulmão - IVc Flocos Higienização quinzenal.

Aumento 200X

Figura 7. Análise histopatológica

Cortes histológicos de pulmão de animais mantidos em forração de gaiolas diferenciadas. A E B representam animais de controle mantidos em maravalha com higienização semanal prevista no manual de procedimentos do Biotério. C E D: animal do Grupo I (maravalha de Pinus), mantido em sistema fechado de rack ventilada (IVC) com higienização quinzenal. E E F: animal do Grupo II (flocos de Pinus), em sistema IVC, com higienização quinzenal. As flechas indicam regiões de congestão e edema.

Fonte: os autores. 


\section{Discussão e Conclusão}

O bem-estar dos animais e seu estado sanitário são amplamente discutidos na pesquisa biomédica e nos centros de criação e experimentação animal, pois há muito encontramos relatos de suas influências nos resultados experimentais [2, 24]. Uma variedade de fatores ambientais podem afetar o sistema neurobiológico dos animais e, consequentemente, suas respostas fisiológicas [3]. Dentre eles, um dos fatores mais importantes é a composição da forração de gaiolas para os animais, que pode influenciar diretamente no microambiente regulando variáveis como temperatura e umidade, importantes na manutenção da homeostase destes.

São diversos os materiais utilizados para a forração de gaiolas. Neste estudo, evidenciamos dois tipos, a maravalha e o flocos, ambas provenientes da madeira de Pinus, porém de gramaturas diferenciadas [25].

Inicialmente, avaliamos a carga microbiana desses materiais, pois, de acordo com a literatura, a forração de gaiolas pode ser considerada uma das maiores fontes de contaminação nas colônias de criação [26]. Nossos resultados demostraram que a maravalha recebida pode ser considerada inapropriada devido ao crescimento de bactérias patogênicas para os animais de laboratório, como é o caso da Klebsiella pneumoniae [27-29]. No que se refere à quantificação do número de micro-organismos no material da forração de gaiolas, são poucos os dados na literatura [12], mas sabe-se que o contato com esses micro-organismos não pertencentes ao hábitat natural do animal pode promover a disbiose e modular sua microbiota e, em consequência, aumentar sua susceptibilidade a doenças [14]. São necessários estudos mais aprofundados quanto à microbiota dos animais após o contato com a forração de gaiolas. Por isso, a maravalha antes de ser utilizada na forração de gaiolas deve ser esterilizada; assim, fornece o ambiente apropriado livres de patógenos, o que garante a saúde dos animais utilizados em estudos de experimentação.

A principal finalidade da forração de gaiolas é absorver a umidade proveniente da urina dos animais, propiciar isolamento térmico e produzir um ambiente apropriado à espécie, em que seja possível aos animais expressarem comportamentos como nidificação, escavação, demarcação de território, entre outros [3,10,12]. Sabe-se que a maioria das instituições de criação e pesquisa seguem os manuais de conduta instituídos por seus conselhos responsáveis [29], que normalmente apontam materiais e tempos de higienização que mostrem uma razão mais apropriada entre custo, benefício e eficácia [21].

Pensando nisso, decidimos avaliar a possibilidade de aumentar o tempo para a higienização dos animais nos dois tipos de forração de gaiolas. Isso porque, segundo alguns autores [21,30], a higienização da gaiola, apesar de necessária, está muito mais ligada ao conceito de sujidade para cada manipulador do que ao próprio animal, o que transforma o conceito em uma particularidade de cada indivíduo. O grande problema está em que a higienização desestrutura o arranjo do microambiente e traz um novo ambiente aos animais, o que causa estresse nestes e elevação das taxas de morbidade e mortalidade. Para que pudéssemos avaliar o tempo adequado para higienização de cada gaiola, optamos por higienização quinzenais. Observamos que, no Grupo II (flocos de Pinus), não houve manifestação de distúrbios relacionados ao estresse, como conflitos, apatia, vocalização, entre outros. Em contrapartida, nos machos do Grupo I (maravalha de Pinus), notamos um alto índice de brigas que pode estar relacionado à escolha do dominante do microambiente [31]. Também avaliamos o grau de sujidade das gaiolas e novamente foi possível observar no Grupo II (flocos de Pinus) que as fezes estavam misturadas ao material, o que trouxe a ideia de menor sujidade; já no Grupo I, havia na gaiola um espaço relacionado ao sanitário, ou seja, foi escolhido um lado da gaiola para os excrementos.

Concluímos, após a observação diária, que os animais da linhagem Balb/c se adaptaram à forração de gaiolas de flocos de Pinus, ao expressarem seu comportamento natural, fisiológico, inclusive no fotoperíodo escuro, em higienizações quinzenais, de acordo com as gravações em período claro e escuro comparado ao grupo com forração de maravalha. Isso não foi visto quando utilizamos a maravalha nos experimentos, não sendo aconselhável sua utilização por um período de tempo maior do que sete dias, já que, após esse período sem higienização, os animais mantinham comportamento mais agressivo, principalmente nos machos, assim como pelos eriçados.

A preocupação ficou acerca da quantidade de amônia inalada por esses animais no período sugerido de 15 dias. Com a avaliação do exame hematológico, os resultados mostraram que os animais não foram acometidos por patologias agudas durante o experimento, independentemente do tipo de material utilizado para 
a formação da forração de gaiolas. Mas, no Grupo i (maravalha de Pinus), os animais apresentaram uma alteração no percentual do hematócrito, parâmetro importante, pois está relacionado a anemias, quando correlacionadas com a hemoglobina e sua diminuição. No caso do seu aumento, sem outras alterações, podemos relacioná-lo a episódios de desidratação e a possíveis alterações cardiovasculares e pulmonares.

A elevação do hematócrito correlacionado ao exame histopatológico trouxe revelações importantes para o nosso trabalho. Os resultados do exame macroscópico dos animais mantidos em sistema fechado IVC (grupo controle), com higienização semanal de acordo com nosso procedimento operacional padrão, mostrou congestão cranial dos lobos frontais direitos sem disseminação. Esse achado foi confirmado posteriormente no exame microscópico que revelou moderada congestão peribronquiolar e alveolar. No Grupo I (maravalha de Pinus), que continha animais higienizados quinzenalmente e em sistema fechado, observamos alterações do lobo superior com disseminação e com pequenos blocos de enfisema. Análise microscópica desse grupo revelou intensa congestão e edema peribronquiolar, não observadas no Grupo iI (flocos de Pinus). Ainda preocupados com a quantidade de amônia, decidimos incluir um grupo de animais mantidos na experimentação em maravalha de Pinus, porém que estavam em sistema aberto. Eles foram mantidos pelo mesmo tempo que os Grupos i e II. De acordo com a Figura 7, esses animais revelaram macro e microscopicamente intensa congestão, edema peribronquiolar e peripleural. Dessa forma, os achados revelam que os animais do grupo controle, do Grupo I (maravalha de Pinus) e os animais necropsiados do sistema aberto apresentaram sugestivas lesões de inflamação pulmonar crônica e síndrome de angústia respiratória aguda [6] e [32].

Ainda existem poucos estudos no Brasil que tentam relacionar o impacto da forração de gaiolas no bem-estar animal, ou mesmo em sua capacidade de modular os resultados experimentais obtidos. Neste trabalho, conseguimos observar a sua importância, tanto no comportamento do animal quanto na saúde dele. No entanto, ainda são necessários estudos relacionados à dosagem de $\mathrm{nh}_{3}$ por gaiola assim como estudos relacionados à modulação da microbiota.

Nossos resultados demonstraram que o flocos de Pinus é uma nova alternativa na criação e na manutenção de camundongos, pois não houve alterações comportamentais dos animais, perda de peso ou patologias agudas. Além disso, o produto se mostrou eficaz para a realização de higienizações quinzenais ao trazer benefícios tanto para os animais quanto para os tratadores e reduzir o número de pessoas envolvidas na criação e na manutenção.

A maravalha de Pinus não foi considerada uma boa opção na higienização semanal ou quinzenal devido às alterações histopatológicas e comportamentais causadas nos animais. Mas, atualmente, esse material é o mais utilizado nas instituições brasileiras, o que causa preocupação, se forem consideradas as manifestações patológicas tardias observadas neste estudo. Além disso, o ivc auxilia na diminuição da influência dos gases e do pó originado no microambiente, e funciona como um retardador dos danos respiratórios. Assim, o mais recomendável é sempre a utilização do sistema ventilado e da higienização quinzenal das gaiolas utilizando o flocos de Pinus.

\section{Referências Bibliográficas}

[1] Kawakami K, Shimosaki S, Tongu M, Kobayashi Y, Nabika T, Nomura M, et al. Evaluation of Bedding and Nesting Materials for Laboratory Mice by Preference Tests. Exp Anim [Internet]. 12 dez. 2007 [acessado 26 out. 2015];56(5):363-8. Disponível em: https://www. jstage.jst.go.jp/article/expanim/56/5/56_5_363/_article

[2] Sakhai SA, Preslik J, Francis DD. Influence of housing variables on the development of stress-sensitive behaviors in the rat. Physiol Behav [Internet]. 2013 15 ago. [acessado 11 nov. 2015];120:156-63. doi: http://doi.org/10.1016/j.physbeh.2013.08.003

[3] Smith AL, Corrow DJ. Modifications to husbandry and housing conditions of laboratory rodents for improved well-being. ilar j [Internet]. 2005;46(2):140-7. Disponível em: https://academic.oup.com/ilarjour$\mathrm{nal} /$ article/46/2/140/910141/Modifications-to-Husbandry-and-Housing-Conditions

[4] Luo K, Zhang H, Zavala F, Biragyn A, Espinosa DA, Markham RB. Fusion of antigen to a dendritic cell targeting chemokine combined with adjuvant yields a malaria dna vaccine with enhanced protective capabilities. PLoS One. 2014;9(3):1-12.

[5] Gaskill BN, Gordon CJ, Pajor EA, Lucas JR, Davis JK, Garner JP. Heat or insulation: behavioral titration of mouse preference for warmth or access to a nest. PLoS One [Internet]. Public Library of Science; jan. 2012 [acessado 16 nov. 2015];7(3):e32799. Disponível em: http://journals.plos.org/plosone/article?id=10.1371/journal.pone.0032799 
[6] Ferrecchia CE, Jensen K, Van Andel R. Intracage ammonia levels in static and individually ventilated cages housing c57bl/6 mice on 4 bedding substrates. J Am Assoc Lab Anim Sci [Internet]. mar. 2014 [acessado 26 out. 2015];53(2):146-51. Disponível em: http:// www.pubmedcentral.nih.gov/articlerender.fcgi?arti$\mathrm{d}=3966270$ \&tool=pmcentrez\&rendertype $=$ abstract

[7] Fabrício VL, Oliveira AHS, Lapchik VBV. Benefícios sanitários do sabugo de milho enriquecido ou não para roedores e técnicas de laboratório [Internet]. Revista da Sociedade Brasileira de Ciência em Animais de Laboratório. 2012 [acessado 12 nov. 2015]; 1(2):169-74. Disponível em: http://revistas.bvs-vet. org.br/RESBCAL/article/view/3113

[8] Broom DM, Molento CFM. Bem-estar animal: conceito e questões relacionadas - revisão. Arch Vet Sci. 2004;9(2):1-11.

[9] Andrade A, Pinto SC, Oliveira RS De. Animais de laboratório criação e experimentação. Rio de Janeiro: Editora Fiocruz; 2002.

[10] Burn CC, Mason GJ. Absorbencies of six different rodent beddings: commercially advertised absorbencies are potentially misleading. Lab Anim [Internet]. sage Publications. 1 jan. 2005 [acessado 26 out. 2015];39(1):68-74. Disponível em: http://lan. sagepub.com/content/39/1/68.abstract

[11] Beauchamp CJ, Boulanger R, Matte J, Saint-Laurent G. Examination of the contaminants and performance of animals fed and bedded using de-inking paper sludge. Arch Environ Contam Toxicol [Internet]. maio 2002 [acessado 12 nov. 2015];42(4):523-8. Disponível em: http://www.ncbi.nlm.nih.gov/pubmed/11994794

[12] Domer DA, Erickson RL, Petty JM, Bergdall VK, Hickman-Davis JM. Processing and treatment of corncob bedding affects cage-change frequency for c57bl/6 mice. J Am Assoc Lab Anim Sci [Internet]. mar. 2012 [acessado 26 out. 2015];51(2):162-9. Disponível em: http://www.pubmedcentral.nih.gov/ articlerender.fcgi? artid=3314518\&tool=pmcentrez\&rendertype $=$ abstract

[13] Ambery AG, Tackett L, Penque BA, Hickman DL, Elmendorf JS. Effect of Corncob bedding on feed conversion efficiency in a high-fat diet-induced prediabetic model in c57bl/6J mice. J Am Assoc Lab Anim Sci [Internet]. set. 2014 [acessado 26 out. 2015];53(5):449-51. Disponível em: http://www. pubmedcentral.nih.gov/articlerender.fcgi?arti$\mathrm{d}=4181685 \&$ tool $=$ pmcentrez\&rendertype $=$ abstract

[14] Ma BW, Bokulich NA, Castillo PA, Kananurak A, Underwood MA, Mills DA, et al. Routine habitat change: a source of unrecognized transient alteration of intestinal microbiota in laboratory mice. PLoS One [Internet]. jan. 2012 [acessado 17 nov. 2015];7(10):e47416. Disponível em: http://www. pubmedcentral.nih.gov/articlerender.fcgi?arti$\mathrm{d}=3474821$ \&tool=pmcentrez\&rendertype $=$ abstract

[15] Leys LJ, McGaraughty S, Radek RJ. Rats housed on corncob bedding show less slow-wave sleep. J Am Assoc Lab Anim Sci [Internet]. nov. 2012 [acessado 17 nov. 2015];51(6):764-8. Disponível em: http:// www.pubmedcentral.nih.gov/articlerender.fcgi?arti$\mathrm{d}=3508179$ \&tool $=$ pmcentrez\&rendertype $=$ abstract

[16] Banks S, Dinges DF. Behavioral and physiological consequences of sleep restriction. J Clin Sleep Med [Internet]. 15 ago. 2007 [acessado 5 set. 2015];3(5):519-28. Disponível em: http://www.pubmedcentral.nih.gov/ articlerender.fcgi?artid=1978335\&tool=pmcen trez\&rendertype $=$ abstract

[17] White NJ, Turner GDH, Medana IM, Dondorp AM, Day NPJ. The murine cerebral malaria phenomenon. Trends Parasitol. 2010;26(1):11-5.

[18] Broom D, Molento C. Bem-estar animal: conceito e questões relacionadas - revisão (Animal welfare: concept and related issues - Review). Arch Vet Sci. 2004;9:1-11.

[19] Ferreira B. Macro e Microambientes. 2002. Em: Andrade A., Pinto SC., Oliveira RS., organizadores. Animais de Laboratório: criação e experimentação [on-line]. Rio de Janeiro: Editora Fiocruz; 2002. p. 54-59.

[20] Chorilli M, Michelin DC, Salgado HRN. Animais de laboratório: o camundongo. Rev Ciencias Farm Basica e Apl. 2007;28(1):11-23.

[21] Rosenbaum MD, VandeWoude S, Johnson TE. Effects of cage-change frequency and bedding volume on mice and their microenvironment. J Am Assoc Lab Anim Sci [Internet]. nov. 2009 [acessado 26 out. 2015];48(6):763-73. Disponível em: http://www. pubmedcentral.nih.gov/articlerender.fcgi?arti$\mathrm{d}=2786931$ \&tool=pmcentrez\&rendertype $=$ abstract

[22] Hoglund AU, Renstrom A. Evaluation of individually ventilated cage systems for laboratory rodents: cage environment and animal health aspects. Lab Anim [Internet]. sage Publications; 1 jan. 2001 [acessado 26 out. 2015];35(1):51-7. Disponível em: http://lan. sagepub.com/content/35/1/51.abstract

[23] Bannoehr J, Franco A, Iurescia M, Battisti A, Fitzgerald JR. Koneman. Koneman's color atlas and textbook of diagnostic microbiology. J Clin Microbiol [Internet]. 2009;47(2):469-71. Disponível em: http:// europepmc.org/backend/ptpmcrender.fcgi?acci$\mathrm{d}=$ PMC1900441\&blobtype $=$ pdf

[24] Kirchner J, Hackbarth H, Stelzer HD, Tsai P-P. Preferences of group-housed female mice regarding structure of softwood bedding. Lab Anim [Internet]. sage Publications; 1 abril 2012 [acessado 11 nov. 2015];46(2):95-100. Disponível em: http://lan.sagepub. com/content/46/2/95.full 
[25] Castelhano-Carlos MJ, Baumans V. The impact of light, noise, cage cleaning and in-house transport on welfare and stress of laboratory rats. Lab Anim [Internet]. sage Publications; 1 out. 2009 [acessado 29 set. 2015];43(4):311-27. Disponível em: http://lan. sagepub.com/content/43/4/311.full

[26] Tanaka T, Ogata A, Inomata A, Nakae D. Effects of different types of bedding materials on behavioral development in laboratory cd1 mice (Mus musculus). Birth Defects Res B Dev Reprod Toxicol [Internet]. out. 2014 [acessado 11 nov. 2015];101(5):393-401. Disponível em: http://www.ncbi.nlm.nih.gov/pubmed $/ 25283888$

[27] Charles River Laboratories International, Inc. Klebsiella species.Technical sheet. 2009. Disponível em: http://www.criver.com/files/pdfs/infectious-agents/ rm_ld_r_klebsiella_spp.aspx

[28] Arama C, Giusti P, Boström S, Dara V, Traore B, Dolo $\mathrm{A}$, et al. Interethnic differences in antigen-presenting cell activation and tlr responses in malian children during Plasmodium falciparum malaria. PLoS One. 2011;6(3):1-11.
[29] Comissão de Ética no Uso de Animais (Ceua) [Internet]. [acessado 22 nov. 2015]. Disponível em: http:// nharvey.icb.usp.br/corpoeditorial/index.php?option $=$ com_content $\&$ view $=$ article\&id $=702$

[30] Burn CC, Peters A, Day MJ, Mason GJ. Long-term effects of cage-cleaning frequency and bedding type on laboratory rat health, welfare, and handleability: a cross-laboratory study. Lab Anim [Internet]. 2006 [acessado 11 ago. 2015];40(4):353-70. Disponível em: http://www.ncbi.nlm.nih.gov/pubmed/17018207

[31] Morato S. O papel da visão na aversão aos espaços abertos no labirinto em cruz elevado. Psicol usp. 2006;17(L):159-74.

[32] Shusterman D. Review of the upper airway, including olfaction, as mediator of symptoms. Environ Health Perspect [Internet]. ago. 2002 [acessado 22 nov. 2015];110 Suppl:649-53. Disponível em: http:// www.pubmedcentral.nih.gov/articlerender.fcgi?arti$\mathrm{d}=1241220 \&$ tool $=$ pmcentrez\&rendertype $=$ abstract 